\title{
The implications of novel oral anticoagulation in ocular surgery
}

\author{
V. Swetha E. Jeganathan ${ }^{1,2 *}$ and Pankaj K. Agarwal ${ }^{3}$ \\ ${ }^{1}$ Department of Ophthalmology, University Hospital Ayr, Scotland, UK \\ ${ }^{2}$ University of Edinburgh, Scotland, UK
}

${ }^{3}$ Department of Ophthalmology, Princess Alexandra Eye Pavilion, Edinburgh, UK

\section{Background}

Anticoagulation drugs play a significant role in modern day surgery- to treat and prevent thromboembolic disease. Warfarin is one of the commonest anti-coagulation used. The dosing of warfarin can be accurately managed by checking international normalized ratio (INR). It is of vital importance when any surgery is planned for a patient so that the dose of warfarin can be adjusted to decrease complication related with bleeding. The advent of new oral anticoagulation therapy with improved safety profile has improved clinical outcomes. However it's difficult to adjust the dosing of oral anticoagulants for any surgery due to lack of monitoring test like INR and subsequently difficult to reverse their anti-coagulant effect. Anti-coagulation needs to be very closely monitored and dose adjusted to avoid any complications of intra-ocular surgery. The clinician's ability to understand appropriate dose management and follow-up decisions will have a deep impact, if such decisions are wrong. There is limited evidence and guideline for use and adjusting the dosage of newer anti-coagulant for intraocular surgery. The aim of this study is to provide evidence-based guidelines for the management of patients receiving novel oral anticoagulant therapy in Ophthalmology practice. A reproducible framework has been created with this guideline that may provide a process to synchronize outpatient anticoagulation supervision. This guideline aims to provide a practical, clinician focused approach to periprocedural anticoagulant management, which is valuable to both ophthalmologists and anesthetists who play a major part in providing local blocks and sedation, monitoring patients and managing life threatening conditions, should the need arise.

\section{New oral anticoagulants (NOACs)}

Until recently, warfarin was the only oral anticoagulant available [1]. The problem is that it requires onerous laboratory monitoring and the list of food and drug interactions is quite wide. It also carries bleeding risk, making the drug unavailable to one-thirds of the patients who should get warfarin. The good news is that already three novel oral anticoagulants: dabigatran (Pradaxa), rivaroxaban (Xarelto) and apixaban (Eliquis) that have been approved recently. These drugs can be suitable alternatives to warfarin. Figure 1 depicts the blood coagulation cascade and the role of anticoagulants [2]. During a disorder of coagulation, it is clinically practical to use of drugs for adjustment of this cascade (Figure 1).

The characteristics of commonly used NOAC drugs are compared in Table 1.

\section{NOACs during anaesthesia}

The European society of anesthesia (ESA) designed a standardized pre-operative questionnaire to identify anti-haemostatic drugs by using the patient's bleeding history and medication history: unfractionated heparin and low-molecular-weight heparins, vitamin K-antagonists, heparinoids, fondaparinux, direct thrombin inhibitors, ADP receptorantagonists, factor $\mathrm{X}$ inhibitors, cyclooxygenase I-inhibitors and glycoprotein IIb/IIIa-inhibitors. Assessment of the patient has to be carried out in advance of elective surgical operations in time for additional logistic, diagnostic and therapeutic outcomes (nerve blockade, individual surgery timing, optimization of coagulation and pro-coagulant therapy and performance of appropriate drug monitoring) [4]. All the patients should be thoroughly informed of their risks of bleeding or thrombosis, prior to consent. The recommendations of ESA on time intervals are chiefly founded on the pharmacology of the concerned anti-hemostatic agents instead of scarce prospective, randomized clinical studies.

\section{NOACs in prevention of venous thromboembolism}

Atrial fibrillation (AF) is a common condition that raises the risk of cerebral thromboembolism. Its prevalence increases with age, resulting in $8 \%$ of people over 80 years of age having AF [5]. Patients with AF are at significant risk of stroke and thromboembolic complications with associated mortality and morbidity. Anticoagulant therapy reduces the risk systemic thromboembolism that leads to transient ischaemic attacks or stroke, the most threatening complications of AF. NOACs (Table 2) are being recommended with increasing frequency as inhibitors of thrombin and activated factor $\mathrm{X}$, and have a number of advantages over conventional warfarin, which includes predictable response, fewer drug and food interactions and little need for monitoring or dose change. Apixaban is an anticoagulant that results in blood coagulation by direct inhibition of activated factor $\mathrm{X}$ (factor Xa), thereby inhibiting thrombin formation [6]. Apixaban has a marketing authorisation for significant prevention of venous thromboembolic events. For the prevention of deep venous thrombosis

Correspondence to: Dr. V. Swetha E. Jeganathan, Department of Ophthalmology, University Hospital Ayr, Dalmellington Road, Ayr, South Ayrshire KA9 6DX, Scotland, UK, E-mail: vswetha@ausdoctors.net

Received: November 09, 2015; Accepted: November 27, 2015; Published: December 01, 2015 


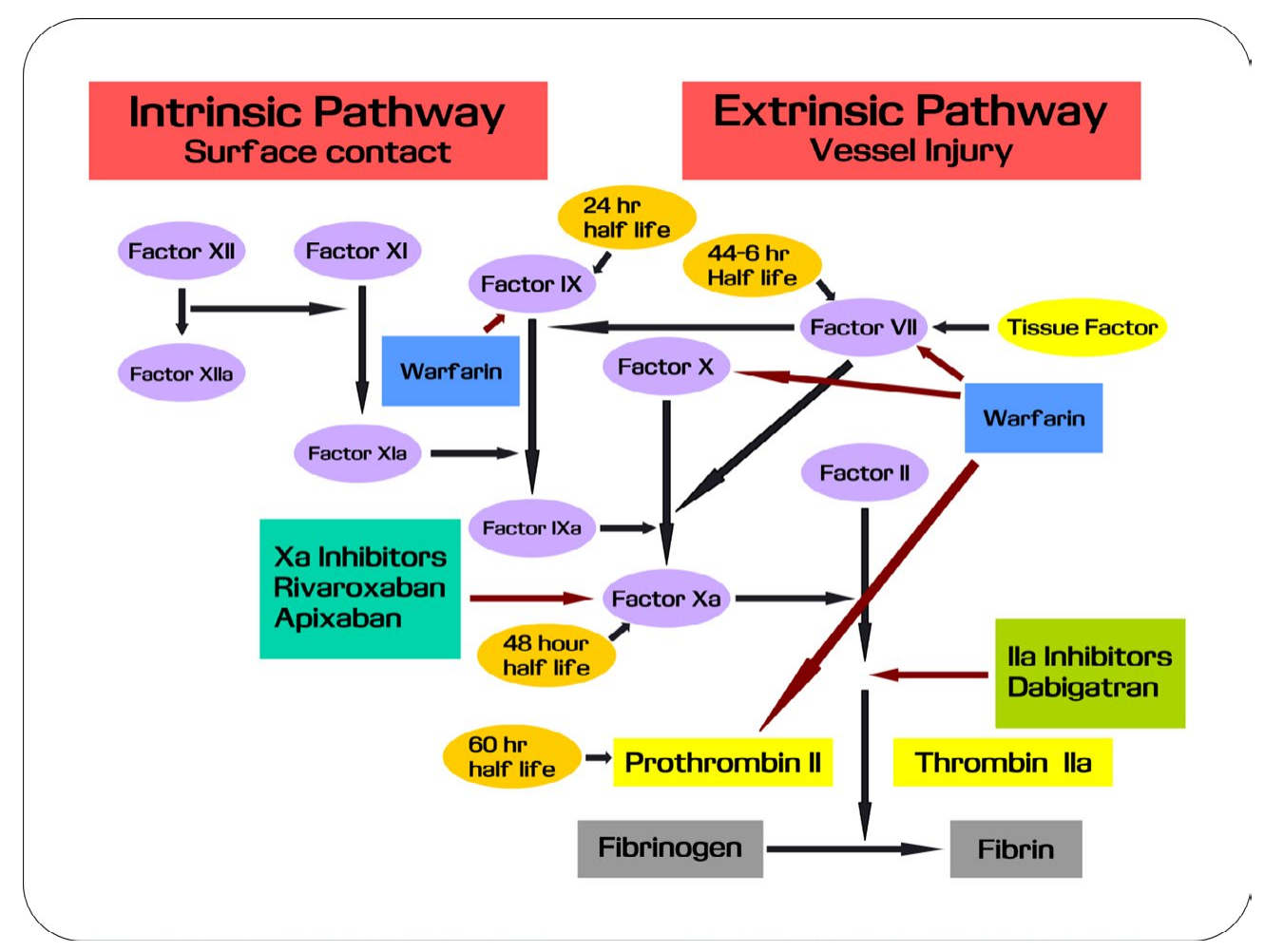

Figure 1. Mechanism of action of oral anticoagulants.

in patients undergoing hip or knee replacement surgery, another NOAC Rivaroxaban is recommended (Table 2).

\section{NOACs in ophthalmic surgery}

There are no clear guidelines in the literature regarding the management of patients' anticoagulated with NOACs. These patients are often elderly and at major risk of life-threatening thromboembolic disorder if anticoagulation is discontinued [8]. Several reports suggest that ophthalmic surgical procedures (with an exception to major lid and orbital surgery) usually correspond to minimal blood loss.

\section{Suggested practice points}

- Patients with coronary stents and prosthetic heart valves should not discontinue anticoagulant agents for cataract surgery.

- A fresh international normalized ratio (INR) result is required to be obtained on the day of surgery, prior to anaesthetic/ surgical intervention.

- The INR must be checked and be in the indicated therapeutic range.

\section{NOACs in cataract surgery}

Cataract operation is one of the most common ophthalmic surgical procedures; the vast majority of the patients are aged with a higher risk of associated systemic disease such as coronary artery disease [9]. Patients with coronary artery disease, hypertension and diabetes are at increased risk of suprachoroidal haemorrhage. In recent years there has been a steady rise in the use of local anaesthetic techniques, but many patients are on antiplatelet or anticoagulant drugs. Emerging data suggest that long-term use of these drugs reduces the risk of thromboembolic disorders in patients with AF and atheroslerotic disease. Several studies suggest that stopping anticoagulant medication, particularly in patients with prosthetic heart valves, AF or recent coronary disease may increase high risk of thromboembolic disorders. This may greatly outweigh the risk of intra or extraocular haemorrhage. Holbrook et al. [10] suggested frequent INR testing during the first couple of weeks of the onset or discontinuation of other medical treatment. Preoperative INR should be tested close to the time of surgery and if there have been any recent changes in the patient's routine medication or diet, then re-checking the INR on the day of surgery is suggested. Although it is reported that most ophthalmic surgical procedures can be safely performed in patients who are therapeutically anticoagulated but proper physician consultation is required, to maintain safe level of anticoagulation for the shortest possible time during surgery [8].

\section{NOACs in vitreoretinal surgery}

At present, there is conflicting evidence of bleeding risk in NOAC patients undergoing vitro-retinal surgery. Continuing of NOACs for patients undergoing vitreoretinal surgery is recommended at present, but the published literature does report certain complications such as subretinal haemorrhage associated with external drainage at the time of scleral buckling procedures. This may occur due to acute hypotony or trauma to choroidal vessels. Spontaneous massive subretinal bleeding in a patient with diabetic retinopathy and on treatment with warfarin 
Table 1. Comparative analysis of the general characteristics of NOACs and current use in medicine [modified from Cupp, 2011] [3].

\begin{tabular}{|c|c|c|c|}
\hline Drug & Dabigatran (Pradaxa) & Rivaroxaban (Xarelto) & Apixaban (Eliquis) \\
\hline Mechanism of action & Direct inhibitor of thrombin & Inhibitor of Factor Xa & Inhibitor of Factor Xa \\
\hline Pharmacokinetics & $\begin{array}{l}\mathrm{T}_{\max }: 1-6 \mathrm{hrs} \\
\text { Half-life: } 12 \text { to } 17 \mathrm{hrs} \\
\text { Dialyzable }(68 \%)\end{array}$ & $\begin{array}{l}\mathrm{T}_{\max }: 2-4 \mathrm{hrs} \\
\text { Half-life: } 5-9 \mathrm{hrs} \\
\text { Excretion: } 66 \% \text { renal } \\
28 \% \text { fecal } \\
\text { Not dialyzable }\end{array}$ & $\begin{array}{l}\mathrm{T}_{\max }: 1-4 \mathrm{hrs} \\
\text { Half-life: } 12 \mathrm{hrs} \\
\text { Excretion: } 25 \% \text { renal } \\
55 \% \text { fecal }\end{array}$ \\
\hline \multirow[t]{2}{*}{ Dosage } & $\begin{array}{l}150 \mathrm{mg} \text { twice a day } \\
75 \mathrm{mg} \text { twice a day in patients with renal } \\
\text { function impairement }\end{array}$ & $\begin{array}{l}\text { NonvalvularAF : } 20 \mathrm{mg} \text { per day with evening } \\
\text { meal } \\
\text { DVT prophylaxis: } 10 \mathrm{mg} \text { per day with or } \\
\text { without food } 6 \text { to } 10 \mathrm{hrs} \text { following surgery. } \\
\text { Treatment for } 12 \text { days and } 35 \text { days following } \\
\text { knee and hip surgery respectively. }\end{array}$ & $\begin{array}{l}2.5 \text { to } 5 \mathrm{mg} \text { twice a day. } \\
\text { Initiation } 12-24 \text { hrs following surgery to } \\
\text { prevent. } \\
\text { Treatment for } 10 \text { to } 14 \text { days following knee } \\
\text { surgery and } 32 \text { to } 38 \\
\text { days following hip surgery. }\end{array}$ \\
\hline & Unchanged excreted in urine. & $\begin{array}{l}\text { Use in patients with moderate to severe } \\
\text { (Child-Pugh class B or C) hepatic disorders } \\
\text { associated with coagulopathy should be } \\
\text { avoided. }\end{array}$ & $\begin{array}{l}\text { Use in patients with mild to moderate (Child- } \\
\text { Pugh class A or B) hepatic disorders should } \\
\text { be avoided. }\end{array}$ \\
\hline $\begin{array}{l}\text { Dosage in hepatic failure } \\
\text { Dosage in renal failure }\end{array}$ & 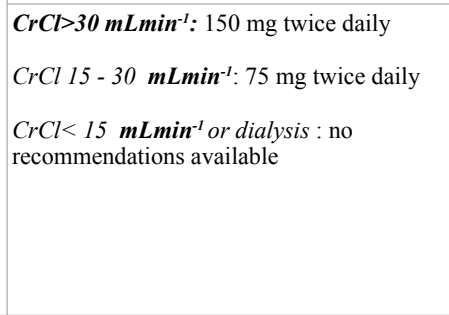 & $\begin{array}{l}\text { Nonvalvular AF: } \\
\text { CrCl>50 mLmin } \\
\text { evening meal }: 20 \mathrm{mg} \text { per day with } \\
\mathrm{CrCl} 15-50 \boldsymbol{m L m i n}^{-1}: 15 \mathrm{mg} \text { per daily with } \\
\text { evening meal } \\
\mathrm{CrCl}<15 \mathbf{m L m i n}^{-1}: \text { Avoid use } \\
\text { DVT prophylaxis: } \\
\mathrm{CrCl}<30 \mathbf{m L m i n}^{-1}: \text { Avoid use }\end{array}$ & $\begin{array}{l}\text { For } \mathrm{CrCl} \geq 30 \mathrm{~mL} / \mathrm{min}: 2.5 \mathrm{mg} \text { twice daily (no } \\
\text { dosage adjustment). } \\
\text { For CrCl } 15-29 \boldsymbol{m L m i n}^{-1} \text { :Use with caution } \\
\text { For } \mathrm{CrCl}<15 \boldsymbol{m L m i n}^{-1}: \text { DO NOT use. }\end{array}$ \\
\hline Advantages & Regular monitoring is not required & Regular monitoring is not required & Regular monitoring is not required \\
\hline Disadvantages & $\begin{array}{l}\text { Irreversible } \\
\text { Drug must be used within } 4 \text { months of } \\
\text { opening and stored in original container }\end{array}$ & Irreversible & Irreversible \\
\hline Adverse effects & $\begin{array}{l}\text { Dyspepsia, GI bleeding, possible increased } \\
\text { risk of MI }\end{array}$ & $\begin{array}{l}\text { Bleeding/hemorrhage/ } \\
\text { hematoma }\end{array}$ & $\begin{array}{l}\text { Bleeding/hemorrhage, nausea, vomiting, } \\
\text { constipation }\end{array}$ \\
\hline Bioavailability & $6.5 \%$ & $80 \%-100 \%$ & $50 \%$ \\
\hline Monitoring & $\begin{array}{l}\text { Bleeding risk can be assessed by the ecarin } \\
\text { clotting time (ECT); mainly used in research } \\
\text { aPTT can provide an approximation of } \\
\text { anticoagulant activity. } \\
\text { Thrombin clotting time (TT) is prolonged in } \\
\text { a dose-dependent fashion and may be useful } \\
\text { to detect presence of dabigatran. }\end{array}$ & $\begin{array}{l}\text { No specific monitoring test is recommended. } \\
\text { Rivaroxaban prolongs aPTT, anti-factor Xa } \\
\text { activity, Neoplastinprothrombin time, and the } \\
\text { HepTest. }\end{array}$ & $\begin{array}{l}\text { Apixaban prolongs aPTT, modified } \\
\text { prothrombin time, and HepTest }\end{array}$ \\
\hline $\begin{array}{l}\text { Conversion to/from other oral/ } \\
\text { parenteral anticoagulants }\end{array}$ & $\begin{array}{l}\text { MPM: Start dabigatran 0-2 hours before } \\
\text { the next dose of parenteral anticoagulant } \\
\text { would have been due or at the time of } \\
\text { discontinuation of intravenous heparin. }\end{array}$ & $\begin{array}{l}\text { MPM: If full anticoagulation dose: Start } \\
\text { rivaroxaban } 0-2 \text { hours before the next dose } \\
\text { of parenteral anticoagulant would have } \\
\text { been due or at the time of discontinuation of } \\
\text { intravenous heparin. }\end{array}$ & $\begin{array}{l}\text { MPM: Start apixaban when the next dose of } \\
\text { parenteral anticoagulant would have been due. }\end{array}$ \\
\hline Management prior to surgery & $\begin{array}{l}\mathrm{CrCl} \geq 50 \mathrm{~mL} / \mathrm{min} \text { : Discontinue dabigatran } \\
1 \text { to } 2 \text { days before procedure } \\
\\
\mathrm{CrCl}<50 \mathrm{~mL} / \mathrm{min} \text { : Discontinue dabigatran } 3 \\
\text { to } 5 \text { days before procedure. } \\
\text { Major procedures, spinal puncture, spinal } \\
\text { or epidural catheter placement may require } \\
\text { discontinuation for a longer period of time. }\end{array}$ & $\begin{array}{l}\text { Discontinue rivaroxaban at least } 24 \text { hours } \\
\text { before surgery. }\end{array}$ & $\begin{array}{l}\text { Discontinue at least } 48 \mathrm{hr} \text { before elective } \\
\text { surgery or invasive procedures with a } \\
\text { moderate or high risk of unacceptable or } \\
\text { clinically significant bleeding } \\
\text { Discontinue at least } 24 \mathrm{hr} \text { before elective } \\
\text { surgery or invasive procedures with a low risk } \\
\text { of unacceptable or where the bleeding would } \\
\text { be noncritical in location and easily controlled }\end{array}$ \\
\hline
\end{tabular}

has been reported [Raj et al., 2003]. In a study by Chauvaud[11] with 60 patients (mean age 73 years) having vitreoretinal surgery under sub-Tenon anaesthesia, one patient had an intraoperative subretinal haemorrhage requiring retinectomy. In another study by Narendran and Williamson [12], 2 out of 7 patients undergoing vitreoretinal surgery while on anticoagulation with warfarin and aspirin suffered hemorrhagic complications, including recurrent vitreous haemorrhage and postoperative hemorrhagicchoroidal detachment.

\section{NOACs in glaucoma surgery}

Patients undergoing glaucoma surgery especially trabeculectomyare at increased risk of haemorrhagic complications with anticoagulation, including suprachoroidal haemorrhage, intrableb bleeding and hyphaema[13]. Patients on anticoagulation throughout glaucoma surgery had the maximum rate of hemorrhagic complications $(31.8 \%)$ compared to patients who discontinued treatment prior to surgery $(\mathrm{P}=.001)$. At present there is no authoritative guideline available for 
Table 2. Oral anticoagulants for prevention of stroke in atrial fibrillation [Khan, 2014] [7].

\begin{tabular}{|l|l|l|l|}
\hline & Apixaban & Dabigatran & Rivaroxaban \\
\hline Dose & $2.5 \mathrm{mg}-5 \mathrm{mg}$ & $110 \mathrm{mg}$ to $150 \mathrm{mg}$ & $10 \mathrm{mg}$ \\
\hline Target & Inhibition of Factor Xa & Inhibition of IIa (thrombin) & Inhibition of Factor Xa \\
\hline Frequency & 2 times daily & 2 times daily & Daily \\
\hline Metabolism & Metabolism of liver $(70 \%)$ & Metabolism of liver $(20 \%)$ & Metabolism of liver $(60 \%)$ \\
\hline
\end{tabular}

management of patients on NOACs undergoing glaucoma surgery, although complications occur more frequently on NOACs. In a questionnaire survey of glaucoma surgeons in England [14], diversity in clinical practice was observed with regard to continuation of anticoagulation therapy with majority of the surgeons not stopping anticoagulation drugs prior to glaucoma surgery.

\section{Other ophthalmic surgeries}

To date there are no known published studies reporting an increased risk of bleeding on NOAC patients undergoing oculoplastic, corneal or squint surgeries.

\section{Guidelines for proper use of NOACs}

The use of newly developed oral anticoagulants (apixaban, dabigatran and rivaroxaban) is recommended to follow the guidelines mentioned below:

- Since all these anticoagulants (NOACs) need dose reduction based on renal function, monitoring of renal function is necessary.

- Carrying out proper adjustments by taking in consideration the metabolic changes that take place with age and other factors that may increase bleeding tendency eg personal history or family history of bleeding disorders, liver failure etc.

- More intensive monitoring of patients during the first months of treatment when control of anticoagulant tends to be less stable.

- The presence of the direct thrombin inhibitor, daebigatran is qualitatively indicated by the activated partial thromboplastin time (APTT).

- Similarly the existence of apixaban and rivaroxaban (both inhibitors of factor $\mathrm{Xa}$ ) are indicated by the prothrombin time (PT).

- Rivaroxaban should always be taken with food while the other NOACs can be taken with or without food.

- In case of patients receiving dronedarone, itraconazole or ketoconazole, the dabigatran dose should be reduced to $75 \mathrm{mg}$ twice daily.

- Patients taking rifampin, ritonavir, or phenytoin should avoid NOACs if possible.

- Warfarin may be preferable over NOAC in patients assumed with low compliance as the anticoagulant effects of NOACs dissipate rapidly 12-24 hours after a dose.

- If there is confirmation of good compliance to NOAC (prescribed treatment for $\geq 3$ weeks preceding cardioversion).
- The NOACs should be withheld for $\geq 24$ hours in patients with normal renal function prior to an elective surgical procedure coupled with a minor bleeding risk and $\geq 48$ hours before surgical procedures associated with a major bleeding risk.

- Apixaban should be discontinued at least 24 hours before surgery in low risk patients and at least 48 hours in moderate to high risk patients and recommenced as soon as possible after the patient's surgery.

- Rivaroxaban should be discontinued at least 24 hours before surgery and recommenced as soon as possible after the patient's surgery.

- Surgery may be required to reverse bleeding due to anticoagulation by NOACs. Intravenous tranexamic acid may be used with haematology input.

\section{Conclusion}

Oral anticoagulation therapy is received by millions of patients to treat or prevent thromboembolic disease. Several significant developments in the last few decades have improved clinical outcomes with NOACs and have resulted in increasing use of this therapy, given its immense promise. Our paper demonstrates the significance of NOAC therapy during ophthalmic surgical procedures and recommends the need for individualization of patient care with respect to anticoagulation, anaesthetic and surgical management.A detailed pre-operative evaluation should be undertaken in these patients to stratify their surgical risk of bleeding. The decision whether to continue NOACs in ophthalmic surgery is complex and needs to incorporate a coordinated, multidisciplinary approach with involvement of ophthalmologists, anaesthetists, haematologists, cardiologists and general practitioners.

\section{Acknowledgment}

The authors thank Dr Ashish Rajan-Satapathy and Dr Duncan Weir, anaesthetists at NHS Lothian for their feedback.

\section{References}

1. Wann LS, Curtis AB, American College of Cardiology Foundation/American Heart Association Task Force. 2011 ACCF/AHA/HRS focused update on the management of patients with atrial fibrillation (update on dabigatran): a report of the American College of Cardiology Foundation/American Heart Association Task Force on practice guidelines. Circulation 123:1144-1150.

2. Sehgal V, Bajwa SJ, Bajaj A (2013) New orally active anticoagulants in critical care and anesthesia practice: The good, the bad and the ugly. Ann Card Anaesth16: 193. [Crossref]

3. Cupp M. Comparison of oral antithrombotics. Pharmacist's Letter/Prescriber's Letter October 2011.

4. Kozek-Langenecker SA. Preoperative coagulation testing. ESA Refresher Course lectures 2008; 06RC1: 49-54. 
5. Camm AJ, Lip GY, De Caterinar, Savelieva I, Atar D, et al. (2010) ESC Guidelines for the management of atrial fibrillation - developed with the special contribution of the European Heart Rhythm Association. Eurospace. 14:1385-1413.

6. Apixaban for the prevention of venous thromboembolism after total hip or knee replacement in adults. NICE technology appraisal guidance 245 (2012).

7. Khan RA (2014) The new oral anticoagulants and management of bleeding. $\mathrm{Br} J$ Cardiol 21: 69-71.

8. McCormack P, Simcock PR, Tullo AB (1993) Management of the anticoagulated patient for ophthalmic surgery. Eye 7: 749-750. [Crossref]

9. Council B (1999) Ophthalmic Anaesthesia. The journal of the British Society of Ophthalmic Anaesthesia.
10. Holbrook AM, Pereira JA, Labiris R, McDonald H, Douketis JD, et al. (2005) Systematic overview of warfarin and its drug and food interactions. Arch Intern Med 165:1095-1106. [Crossref]

11. Chauvaud D (2006) Anticoagulation and vitreoretinal surgery. Bull Acad Natl Med 191: 879-884.[Crossref]

12. Narendran N, Williamson TH (2003) The effects of aspirin and warfarin therapy on haemorrhage in vitreoretinal surgery. Acta Ophthalmol Scand 81: 38-40.[Crossref]

13. Law SK, Song BJ, Yu F, Kurbanyan K, Yang TA, et al. (2008) Hemorrhagic complications from glaucoma surgery in patients on anticoagulation therapy or antiplatelet therapy. Am J Ophthalmol 145: 736-746.[Crossref]

14. AlwitryA, King AJ, Vernon SA (2008) Anticoagulation therapy in glaucoma surgery. Graefes Arch Clin Exp Ophthalmol 246: 891-896. [Crossref]

Copyright: (C2015 Jeganathan VSE. This is an open-access article distributed under the terms of the Creative Commons Attribution License, which permits unrestricted use, distribution, and reproduction in any medium, provided the original author and source are credited. 